\title{
Increase of Oxidative Stress and Accumulation of a-Synuclein in Wistar Rat's Midbrain Treated with Rotenone
}

\author{
Arief Budi Yulianti ${ }^{1}$, Sony Heru Sumarsono ${ }^{2}$, Ahmad Ridwan $^{2}$ \& Ayda T. Yusuf ${ }^{2}$ \\ ${ }^{1}$ Medical Biology, Faculty of Medicine, Bandung Islamic University, \\ Jalan Hariangbanga No. 2, Bandung 40116, Indonesia \\ ${ }^{2}$ Research Group of Physiology, Developmental Biology and Biomedical Science, \\ School of Life Science and Technology, Bandung Institute of Technology \\ Jalan Ganesha No. 10, Bandung 40132, Indonesia \\ Email: iyoelfk@yahoo.ca; budi.yulifk@gmail.com
}

\begin{abstract}
A neurodegenerative disorder caused by oxidative stress leads to an accumulation of $\alpha$-synuclein on neurons. Here, we report our findings on the effect of rotenone on the increase of oxidative stress and accumulation of $\alpha$ synuclein in the midbrain of Wistar rats. Thirty six male rats (8-9 weeks, 200$250 \mathrm{~g}$ ) were divided into three groups: the Blank group, the Solvent-rotenone group (intraperitoneally injected with $1 \mathrm{ml} / \mathrm{kg}$ body weight of sunflower seed oil), and the Rotenone group (intraperitoneally injected with $2.5 \mathrm{mg} / \mathrm{kg}$ body weight of rotenone) for 9, 19, and 28 days. The rats were decapitated on day 10 for the 9-day treatment, day 20 for the 19-day treatment, day 30, 40, 50 and 60 for the 28-day treatment ( 2 rats/group or 6 rats/day of observation time). The midbrains were isolated and extracted. Glutathione assay and $\alpha$-synuclein ELISA tests were performed. The results showed that the average oxidative stress index was highest in the Blank group $(0.95 \pm 0.24,0.63 \pm 0.23,0.81 \pm 0.27$, respectively). Meanwhile, the concentration of $\alpha$-Synuclein had decreased in all groups $(0.09 \pm 0.03,0.15 \pm 0.03$, and $0.13 \pm 0.02 \mathrm{ng} / \mathrm{mg}$ tissue, respectively). Correlation analysis showed that the oxidative stress index was inversely proportional to the concentration of $\alpha$-synuclein. Our conclusion is that the midbrain of Wistar rats treated with rotenone indicated oxidative stress and led to an accumulation of $\alpha$-synuclein protein.
\end{abstract}

Keyword: $\alpha$-synuclein; antioxidant; neurodegeneration; oxidative stress; rotenone.

\section{$1 \quad$ Introduction}

Parkinson's disease (PD) is a neurodegenerative disorder that leads to clinical symptoms such as resting tremor, muscle rigidity, bradykinesia and postural instability [1-4]. Histopathological characteristics found are cytoplasmic inclusion bodies in substantia nigra, called Lewy bodies (LB). The main component of Lewy bodies is $\alpha$-synuclein [5-6].

Copyright ( 2012 Published by LPPM ITB, ISSN: 1978-3043, DOI: 10.5614/itbj.sci.2012.44.4.3 
$\alpha$-Synuclein is a presynaptic terminal protein that is an unfolding protein acting as a molecular chaperone, which could be involved in protein-protein interactions [7]. A very important clue is the role of $\alpha$-synuclein that interacts directly in the membrane surface. Thus it is possible that $\alpha$-synuclein is a regulatory component of vesicular transport proteins [7-10].

$\alpha$-Synuclein is a small protein, with a length of only 140 amino acids and it is water-soluble. This protein has the structure of a monomer that can form oligomers or fibrils that may become toxic to neurons [10]. The mechanism triggering the structural transition of $\alpha$-synuclein to form the cytoplasmic inclusion called LB is still unclear [5,9]. Further investigation is needed.

The change of the $\alpha$-Synuclein structure could be caused by the oxidative stress on the neuron, where the levels of reactive oxygen species (ROS) exceed the antioxidant capacity of the cell [11]. Defects in oxygen metabolism may contribute $1 \%$ superoxide $\left(\mathrm{O}_{2}{ }^{*}\right)$ or hydrogen peroxide of all the oxygen present in a cell [11-12]. Superoxide stimulates cells to produce nitrogen oxide (NO) and then react to produce peroxynitrite $\left(\mathrm{ONOO}^{-}\right)$, a strong oxidant that can react with carbon dioxide $\left(\mathrm{CO}_{2}\right)$ to produce nitrotyrosine, causing the formation of water insoluble aggregates of $\alpha$-synuclein [12].

Rats as the animal model were given neurotoxin rotenone (a natural pesticide from the root of Derris sp) in order to generate oxidative stress in the midbrain for investigating whether it will induce accumulation of $\alpha$-synuclein in the neuron. Rotenone is a lipophilic neurotoxin and thus it easily penetrates into the cell membrane, and is predicted to increase the accumulation of $\alpha$-synuclein insoluble aggregates. This paper focuses on the correlation between the levels of the oxidative stress index and $\alpha$-synuclein concentration in the midbrain of the rats.

\section{$2 \quad$ Materials and Methods}

\subsection{Materials}

Rotenone (R 8875), sunflower seed oil (S5007), DTNB (D8130), L Glutathione Reduced (G4251), Glutathione Reductase (G3664), NADPH (N5130) were purchased from Sigma Aldrich, while Rat $\alpha$-Synuclein ELISA Kit (MBS722815) was purchased from MyBioSource; other substances, such as Phosphate Buffer Saline, $\mathrm{pH}$ 7.4, Tris Base and Tris HCL, Phosphate buffer, $\mathrm{pH}$ 7.0, and others, were purchased from Merck. 


\subsection{Animals}

Wistar rats were bred and kept alive in an animal house (Rumah Hewan) SITH ITB, the room temperature was maintained at $22-28^{\circ} \mathrm{C}$ with a humidity of approximately $80 \%$, while the light and dark periods were $12 / 12$ hours. The rats were fed with CP 551 from Charoen Pokphand Indonesia. Food and water were given ad libitum. All experimental procedures were conducted in accord with Ethical Clearance from Health Research Ethics Committee, Faculty of Medicine UNPAD-dr Hasan Sadikin General Hospital Bandung.

\subsection{Methods}

Thirty six (36) male Wistar rats, aged 8-9 weeks, weight 200-250 g were divided into three groups: (i) the Blank group, (ii) the Solvent-rotenone group, and (iii) the Rotenone group. The Blank group was not given any treatment, while the Solvent-rotenone group was injected daily with $1 \mathrm{ml} / \mathrm{kg}$ body weight of sunflower seed oil, and the Rotenone group was intraperitoneally injected daily with $2.5 \mathrm{mg} / \mathrm{kg}$ body weight of rotenone. The rats were weighed daily, and for the Rotenone group, if rats showed signs of dehydration, they were given Ringer lactate subcutaneously. The rats were decapitated and dissected on day 10 for the 9-day treatment, day 20 for the 19-day treatment, day 30, 40, 50 and 60 for the 28-day treatment ( 2 rats/group or 6 rats/day of observation). The midbrain was isolated into cryotubes and immediately frozen in liquid nitrogen.

\section{$2.4 \quad$ Protein Isolation}

The samples were thawed and transferred into $2 \mathrm{ml}$ Eppendrof tubes, then washed with $160 \mathrm{mg} / \mathrm{L}$ heparin in PBS, repeated twice, and then mashed using a homogenizer. Phosphate buffer ( $\mathrm{pH}$ 7.0) was added into the tubes to reach a final volume of $2 \mathrm{ml}$. The tubes were then centrifuged at $14.000 \mathrm{rpm}$ for 10 minutes at $4{ }^{\circ} \mathrm{C}$. Supernatant was isolated for the analysis of reduced glutathione (GSH) and total glutathione using a Glutathione Assay Kit [13], and analysis of $\alpha$-synuclein using an $\alpha$-synuclein ELISA Kit.

The principle of the GSH assay is measurement of the sulfhydril bond/thiol group with the Sedlak and Linsay method [13]. Trichloroacetic acid (TCA) was added into the supernatant to precipitate the protein. The reaction between Sulfhydril bonds with DTNB/Elman's reagent will appear yellow and is measured through the use of a UV spectrophotometer, using a $412 \mathrm{~nm}$ wavelength ( $\lambda$ ). Measurement of total GSH is performed with a similar procedure, completed with glutathione reductase and NADPH addition.

Relationship among GSH, GSSG and Total GSH follow this formula,

$$
\mathrm{GSH}_{\mathrm{tot}}=\mathrm{GSH}+\mathrm{GSSG}
$$


The principle of the $\alpha$-synuclein assay is as follows: wells are coated with polyclonal anti $\alpha$-synuclein for quantitative measurement. The samples and buffer are incubated together with $\alpha$-synuclein (HRP) conjugate for one hour and then decanted and washed five times. After that, the wells are incubated with a substrate for HRP enzyme, and a blue color will appear. Finally, a stop solution is added to stop the reaction, and the color will become yellow. The intensity of the color is measured with a microplate reader using a $450 \mathrm{~nm}$ wavelength.

\subsection{Statistical Analysis}

Data were processed with SPSS version 17.

\section{Results}

\subsection{Body Weight}

The rats' body weight was used for monitoring growth, so that the effects of the neurotoxin used in this research could be detected early. The body weight of the Blank group tended to increase with age (Figure 1). The average body weight was $264.59 \pm 17.73 \mathrm{~g}$. The body weight in the Solvent-rotenone group and Rotenone group tended to increase with age, with an average of $292.19 \pm 27.52$ $\mathrm{g}$ and $256.75 \pm 17.14 \mathrm{~g}$, respectively (Figure 2 and Figure 3). Under normal conditions, the average body weight of male Wistar rats is approximately $275 \mathrm{~g}$. In the Blank group, the rats' body weight was similar to the normal weight; in the Solvent-rotenone group the weight was higher than normal, whereas in the Rotenone group the weight was lower than the normal weight. Sunflower seed oil caused an increase of body weight, while rotenone slightly decreased it [14].

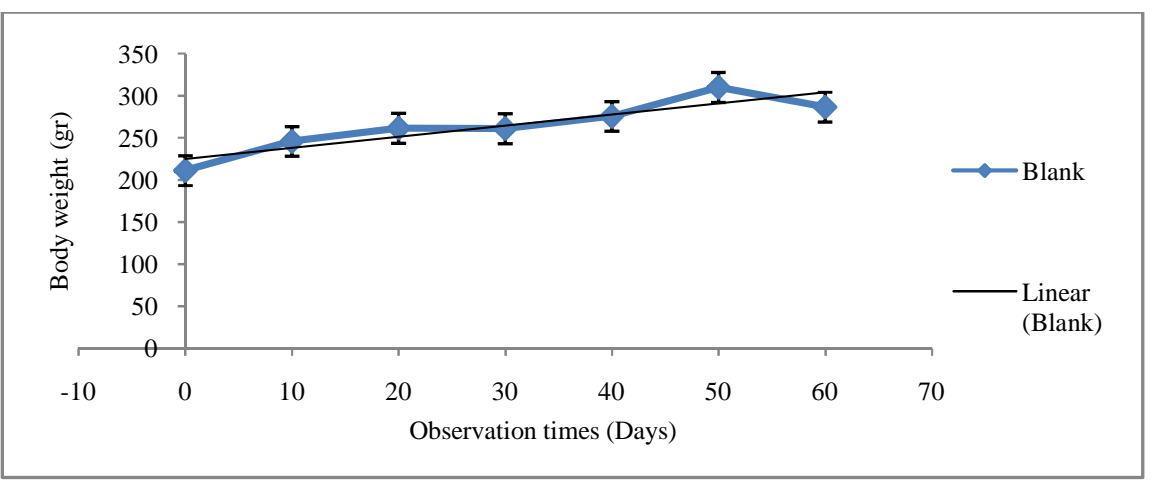

Figure 1 Rat's body weight in the Blank group tended to increase with age, with an average of $264.59 \pm 17.73 \mathrm{~g}$. The line with squares indicates the actual data of the body weight; the straight line is the linear approximation of the body weight. 


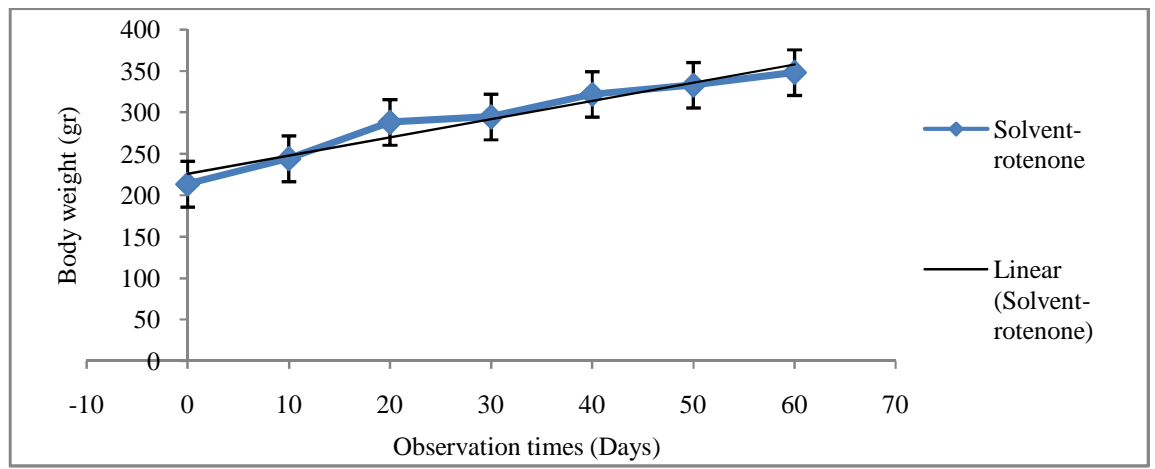

Figure 2 Rat's body weight in the Solvent-rotenone group tended to increase with age, with an average of $292.19 \pm 27.52 \mathrm{~g}$. The line with squares indicates the actual data of the body weight; the straight line is the linear approximation of the body weight.

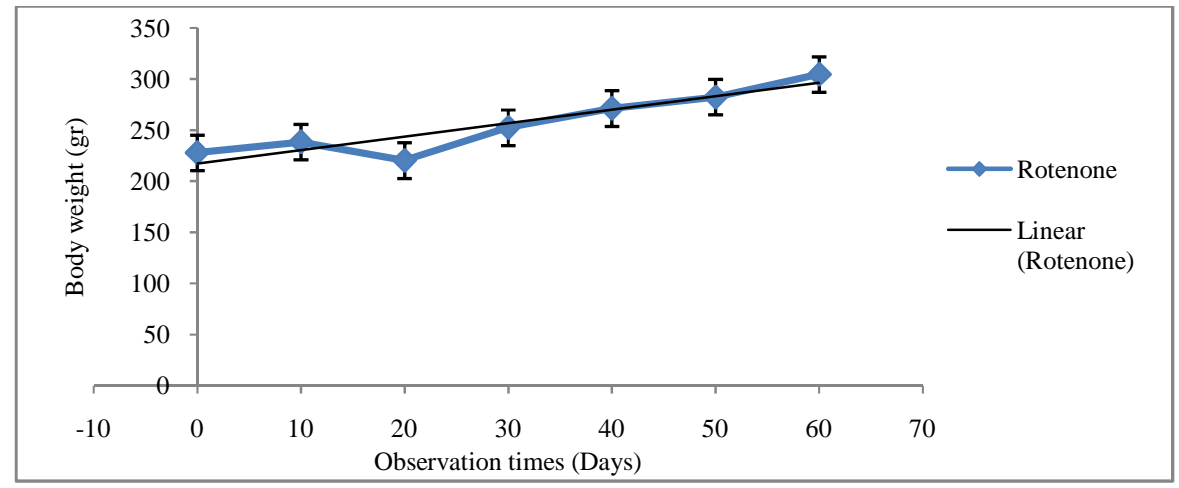

Figure 3 Rat's body weight in the Rotenone group tended to increase with age, with an average of $256.75 \pm 17.14 \mathrm{~g}$. The line with squares indicates the actual data of the body weight; the straight line is the linear approximation of the body weight.

\subsection{Reduced Glutathione (GSH)}

The GSH concentrations in the midbrain of the normal rats and the treated rats are shown in Figures 4-5. GSH as an endogenous antioxidant plays a role in scavenging free radicals such as superoxide, hydrogen peroxide and proxynitrite. Therefore, the main function of GSH is to maintain the balance of redox homeostasis [15]. Based on the observation time, the GSH concentration tends to increase parallel with age (Figure 1). We found that the highest concentration of GSH in the Blank group was on day $30(5.04 \mu \mathrm{mol} / \mathrm{mg}$ tissue $)$ with an average of $4.16 \pm 0.46 \mu \mathrm{mol} / \mathrm{mg}$ tissue (Figure 4). Meanwhile, in the Solvent-rotenone group it tended to increase slightly, with the highest value on 
day $40(7.12 \mu \mathrm{mol} / \mathrm{mg}$ tissue $)$ and an average of $4.47 \pm 0.76 \mu \mathrm{mol} / \mathrm{mg}$ tissue (Figure 5). These data indicate that the sunflower seed oil may have delayed the increase of the GSH. But in the Rotenone group the concentration of GSH tended to decrease, with the highest value on day $10(6.36 \mu \mathrm{mol} / \mathrm{mg}$ tissue $)$ and an average of $4.44 \pm 0.61 \mu \mathrm{mol} / \mathrm{mg}$ tissue (Figure 6). These data show that the induction of rotenone in the midbrain after 9 days of treatment was responded by a decrease of GSH. These data also indicate that the rotenone affected the GSH concentration directly during the 9 days of treatment and caused oxidative stress in the midbrain.

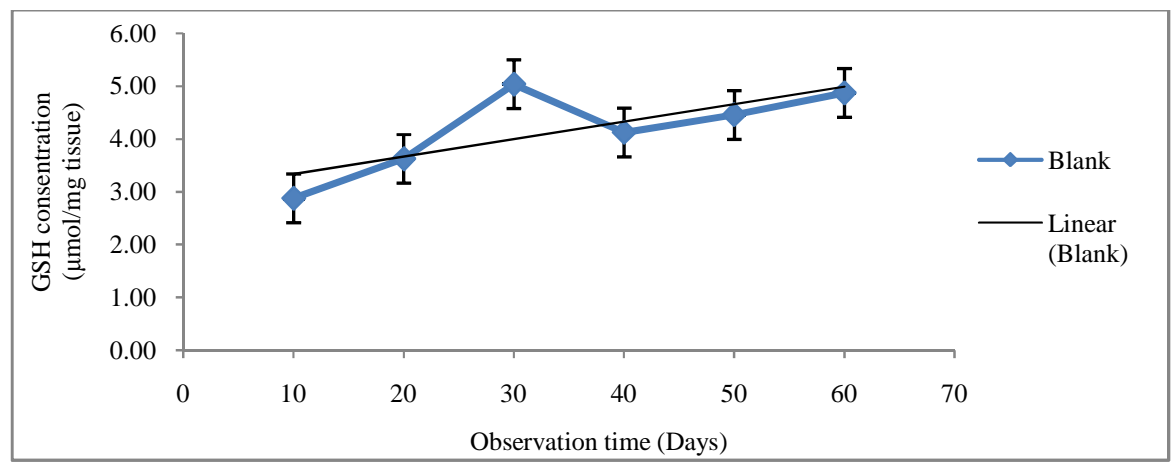

Figure 4 The GSH concentration of the rats' midbrain in the Blank group tended to increase, with the highest GSH concentration on day $30(5.04 \mu \mathrm{mol} / \mathrm{mg}$ tissue) and an average of $4.16 \pm 0.46 \mu \mathrm{mol} / \mathrm{mg}$ tissue. The line with squares indicates the actual data of the GSH concentration; the straight line is the linear approximation of the GSH concentration.

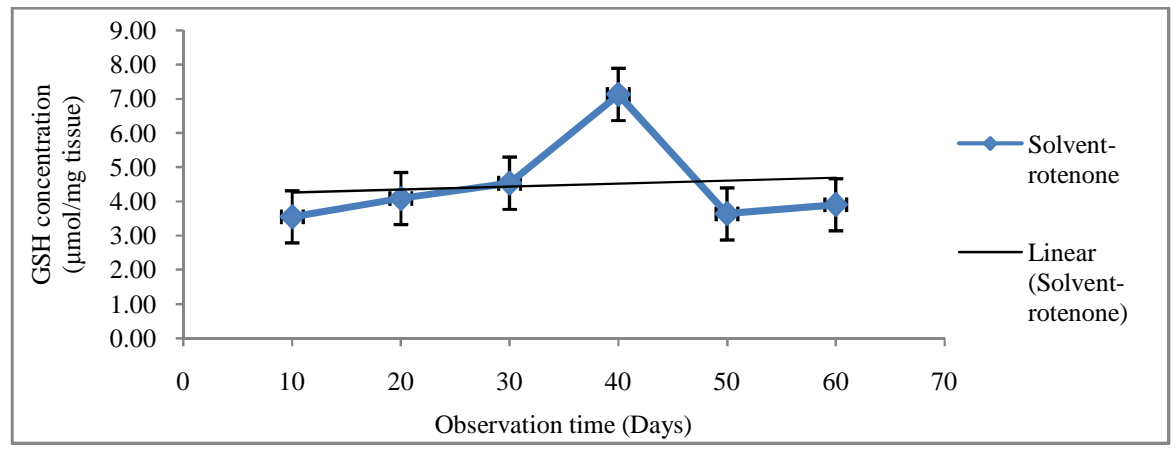

Figure 5 The GSH concentration of the rats' midbrain in the Solvent-rotenone group tended to increase, with the highest GSH concentration on day 40 (7.12 $\mu \mathrm{mol} / \mathrm{mg}$ tissue) and an average of $4.47 \pm 0.76 \mu \mathrm{mol} / \mathrm{mg}$ tissue. The line with squares indicates the actual data of the GSH concentration; the straight line is the linear approximation of the GSH concentration. 


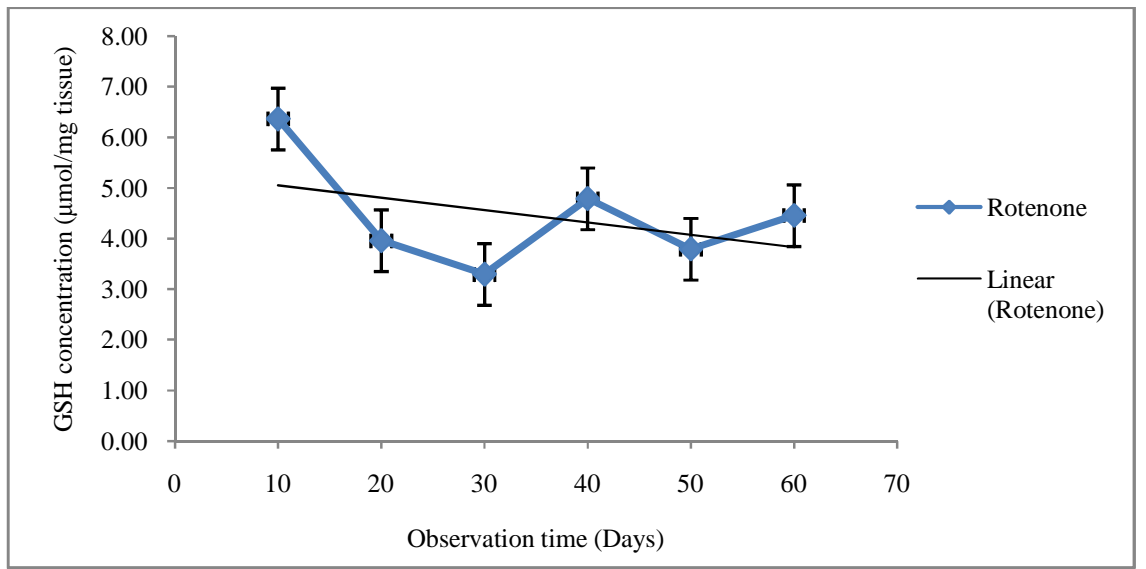

Figure 6 The GSH concentration of the rats' midbrain in the Rotenone group tended to decrease, with the highest GSH concentration on day 10 (6.36 $\mu \mathrm{mol} / \mathrm{mg}$ tissue) and an average of $4.44 \pm 0.61 \mu \mathrm{mol} / \mathrm{mg}$ tissue. The line with squares indicates the actual data of the GSH concentration; the straight line is the linear approximation of the GSH concentration.

\subsection{Oxidized Glutathione (GSSG)}

The GSSG concentrations in the midbrain of the normal rats and the treated rats are shown in Figure 7-9. Inside the cells, GSSG molecules are changed into GSH molecules by glutathione reductase and NADPH. GSH and GSSG are efficient cellular redox systems [13,15]. If an increase of the GSSG concentration is not followed by an increase of the GSH concentration it means that the redox system in the cell is disrupted and cells are in an oxidative stress condition. Based on the observation time, the GSSG concentration in the Blank group tended to decrease contrary to the body weight (Figure 1), with the highest GSSG concentration was on day $20(6.23 \mu \mathrm{mol} / \mathrm{mg}$ tissue $)$ and an average of $3.71 \pm 0.86 \mu \mathrm{mol} / \mathrm{mg}$ tissue (Figure 7). However, in the Solventrotenone group the GSSG concentration tended to increase, with the highest value on day $60(6.08 \mu \mathrm{mol} / \mathrm{mg}$ tissue $)$ and an average of $2.57 \pm 0.98 \mu \mathrm{mol} / \mathrm{mg}$ tissue (Figure 8). Meanwhile, in the Rotenone group, it tended to increase, with the highest value on day $50(5.81 \mu \mathrm{mol} / \mathrm{mg}$ tissue $)$ and an average of $3.14 \pm 0.94$ $\mu \mathrm{mol} / \mathrm{mg}$ tissue (Figure 9). Under normal conditions, GSSG molecules are converted into GSH molecules [15], so that the GSSG concentration decreases with age. However, sunflower seed oil affecting the GSSG concentration is found in our data; the GSSG concentration increased gradually with age. Rotenone had the same effect on the GSSG concentration. 


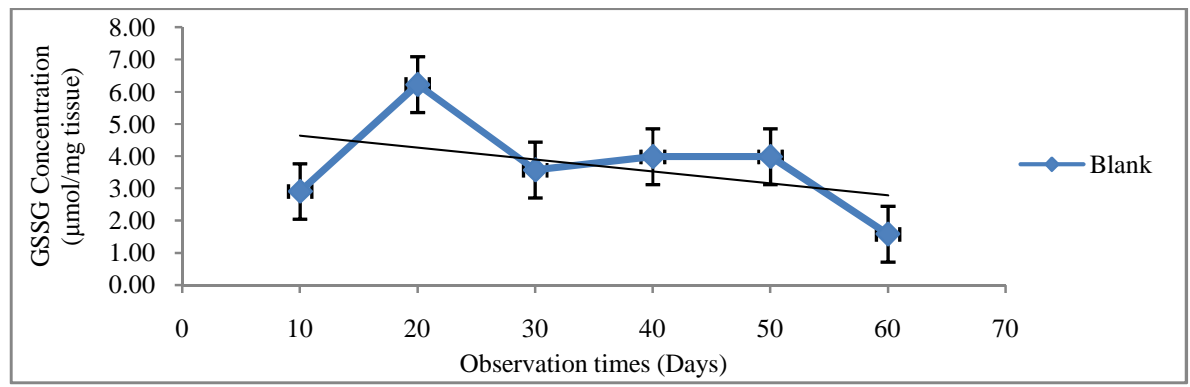

Figure 7 The GSSH concentration of the rat's midbrain in the Blank Group tends to decrease, with the highest GSSH concentration on day 20 (6.23 $\mu \mathrm{mol} / \mathrm{mg}$ tissue) and an average of $3.71 \pm 0.86 \mu \mathrm{mol} / \mathrm{mg}$ tissue. The line with squares is the actual data of GSSH concentration; the straight line is the liniar approximation of GSSH concentration.

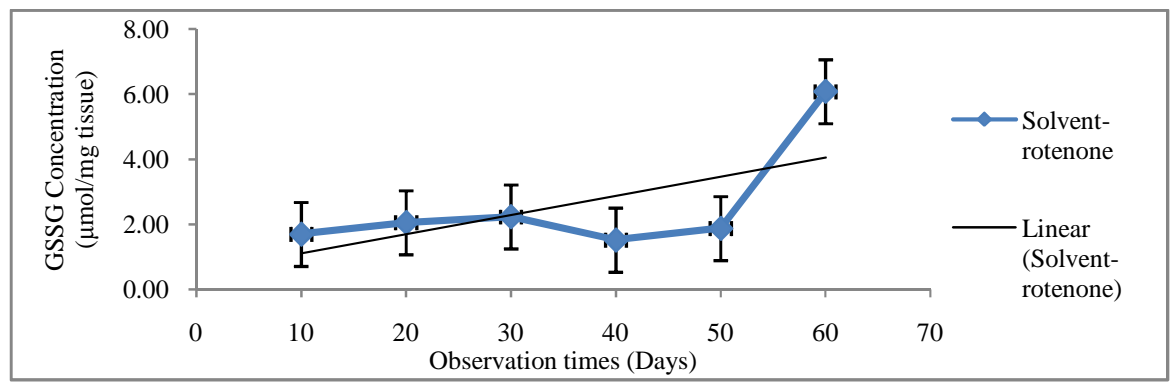

Figure 8 The GSSH concentration of the rat's midbrain in the Solvent-rotenone group tended to increase, with the highest GSSH concentration on day 60 (6.08 $\mu \mathrm{mol} / \mathrm{mg}$ tissue) and an average of $2.57 \pm 0.98 \mu \mathrm{mol} / \mathrm{mg}$ tissue. The line with squares is the actual data of GSSH concentration; the straight line is the linear approximation of GSSH concentration.

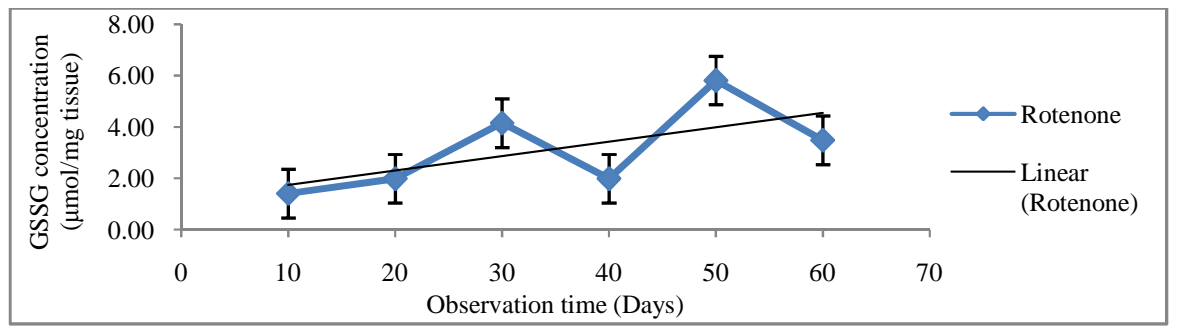

Figure 9 The GSSH concentration of the rat's midbrain in the Rotenone group tended to increase, with the highest GSSH concentration on day 50 (5.81 $\mu \mathrm{mol} / \mathrm{mg}$ tissue) and an average of $3.14 \pm 0.94 \mu \mathrm{mol} / \mathrm{mg}$ tissue. The line with squares is the actual data of GSSH concentration; the straight line is the linear approximation of GSSH concentration. 


\subsection{Oxidative Stress Index (OSI)}

The oxidative stress index (OSI) in the midbrain of the normal rats and the treated rats is shown in Figure 10-12. The OSI is a ratio of GSSG to GSH that describes the oxidative stress conditions in a cell. Under normal conditions, the ratio between the GSH concentration and the GSSG concentration is 0.9 to 0.1 , or the oxidative stress index is $0.11[13,15,16]$. Based on the observation time, the OSI in the Blank group tended to decrease, with the highest value on day 20 (1.60) and an average of $0.95 \pm 0.24$ (Figure 10). However, in the Solventrotenone group, it tended to increase, with the highest value on day 60 (1.43) and an average of $0.63 \pm 0.23$ (Figure 11). Meanwhile, in the Rotenone group it tended to increase, with the highest value on day 50 (1.45) and an average of $0.81 \pm 0.27$ (Figure 12). The OSI trends (Figure 10-12) were proportional to the GSSG trends (Figure 7-9), and inversely proportional to the GSH trends (Figure 4-6). As shown in our data, under normal conditions, the OSI of the midbrain tended to decrease with age, but tended to increase due to rotenone or sunflower seed oil. The rotenone interfered by blocking the mitochondria complex I [17]. Yet, the sunflower seed oil as solvent interfered too. Though sunflower seed oil has a high nutritional value, it may have disturbed the fat metabolism.

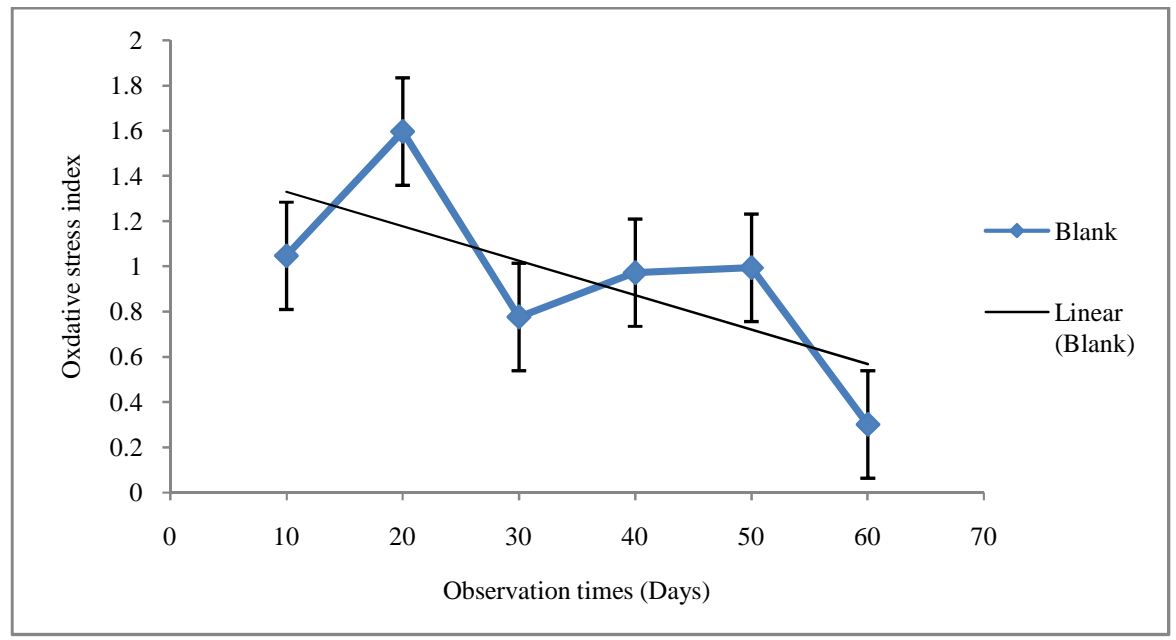

Figure 10 The oxidative stress index of the rat's midbrain in the Blank group tended to decrease, with the highest oxidative stress index occurred on day 20 (1.60) and an average of $0.95 \pm 0.24$. The line with squares is the actual data of oxidative stress index; the straight line is the linear approximation of oxidative stress index. 


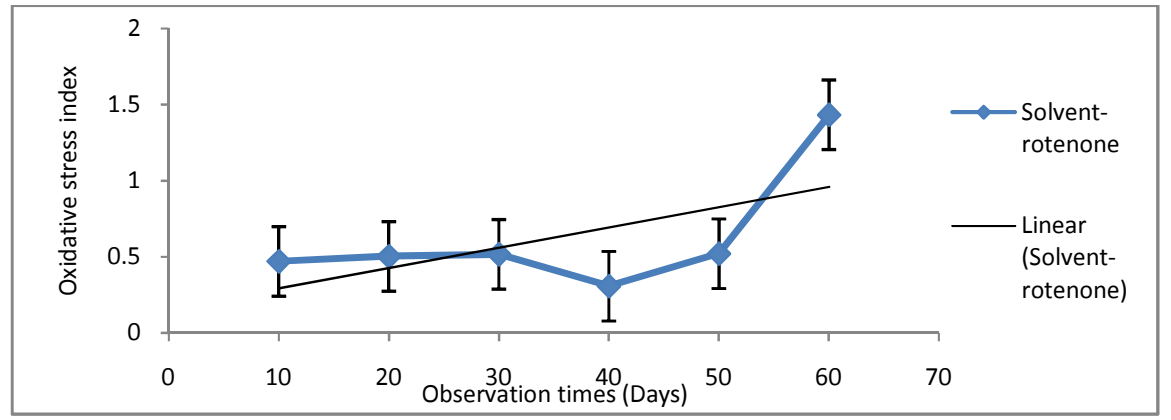

Figure 11 The oxidative stress index of the rat's midbrain in the Solventrotenone group tended to increase, with the highest oxidative stress index on day 60 (1.43) and an average of $0.63 \pm 0.23$. The line with squares is the actual data of oxidative stress index; the straight line is the linear approximation of oxidative stress index.

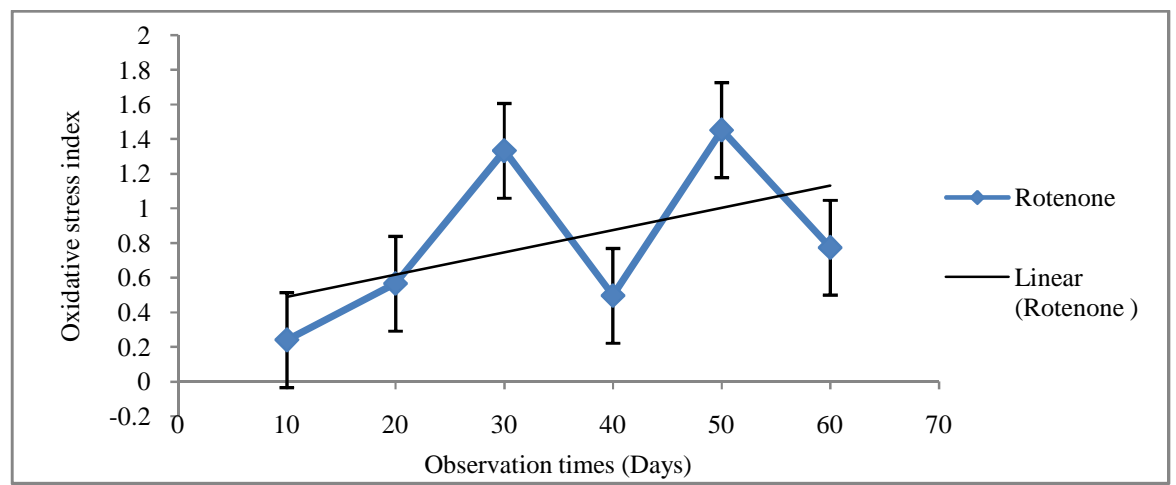

Figure 12 The oxidative stress index of the rat's midbrain in the Rotenone group tended to increase, with the highest oxidative stress index on day 50 (1.45) and an average of $0.81 \pm 0.27$. The line with squares is the actual data of oxidative stress index; the straight line is the linear approximation of oxidative stress index.

\section{5 $\quad \alpha-S y n u c l e i n$}

The $\alpha$-synuclein concentration in the midbrain of the normal rats and the treated rats is shown in Figure 13-15. Under normal conditions, the structure of $\alpha$ synuclein is monomeric, water-soluble and available in the cytosol of the neuron. But under toxic conditions, $\alpha$ - synuclein becomes aggregate and waterinsoluble [18]. Based on the observation time, the $\alpha$-synuclein concentration in Blank Group tended to decrease, with the highest value on day $10(0.18 \mathrm{ng} / \mathrm{mg}$ tissue) and an average of $0.09 \pm 0.03 \mathrm{ng} / \mathrm{mg}$ tissue (Figure 13). Meanwhile, in 
the Solvent-rotenone group, it tended to decrease, with the highest value on day $10(0.22 \mathrm{ng} / \mathrm{mg}$ tissue) and an average of $0.15 \pm 0.03$ (Figure 14). Similarly, in the Rotenone group, it tended to decrease, with the highest value on day 10 $(0.17 \mathrm{ng} / \mathrm{mg}$ tissue) and an average of $0.13 \pm 0.02 \mathrm{ng} / \mathrm{mg}$ tissue. As shown in our data, in all groups the $\alpha$-synuclein concentration tended to decrease with age, although under normal conditions it was lower than in the Rotenone group or the Solvent-rotenone group. The $\alpha$-synuclein concentration was higher in the Solvent-rotenone group than in the Rotenone group. This should be a concern. Our notion is that changes occurred in the $\alpha$-synuclein solubility.

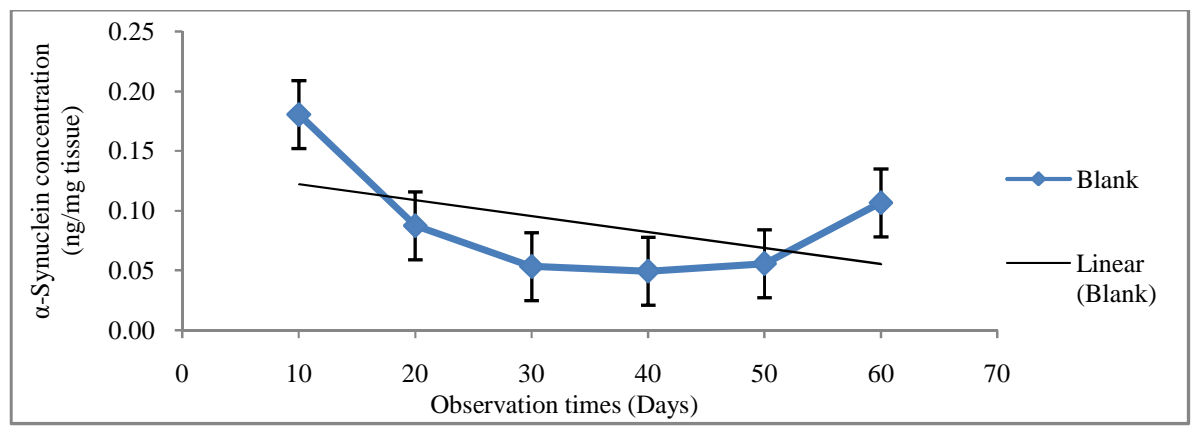

Figure 13 The $\alpha$-synuclein concentration of the rat's midbrain in the Blank group tended to decrease, with the highest $\alpha$-synuclein concentration on day 10 $(0.18 \mathrm{ng} / \mathrm{mg}$ tissue $)$ and an average of $0.09 \pm 0.03 \mathrm{ng} / \mathrm{mg}$ tissue. The line with squares is the actual data of $\alpha$-synuclein concentration; the straight line is the linear approximation of $\alpha$-synuclein concentration.

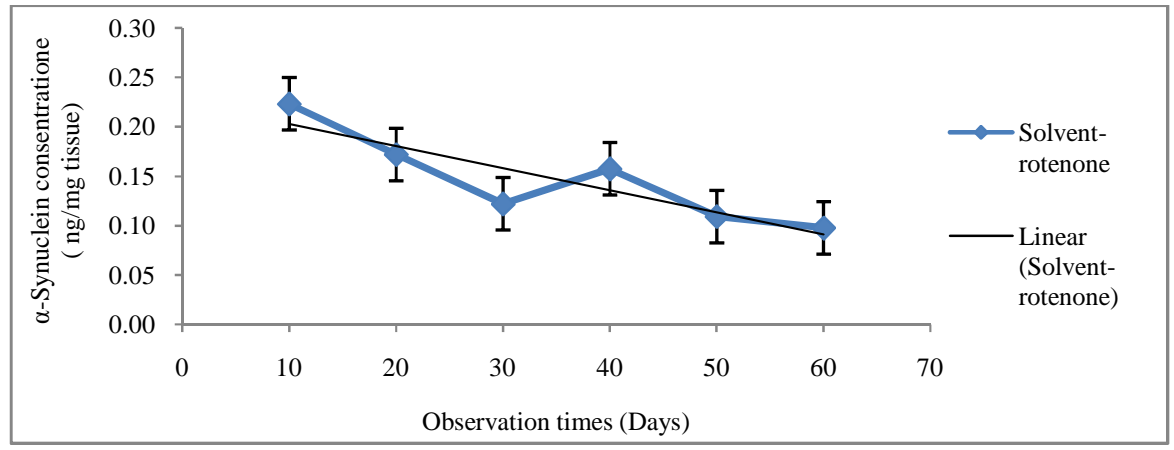

Figure 14 The $\alpha$-synuclein concentration of the rat's midbrain in the Solventrotenone group tended to decrease, with the highest $\alpha$-synuclein concentration on day $10(0.22 \mathrm{ng} / \mathrm{mg}$ tissue $)$ and an average of $0.15 \pm 0.03 \mathrm{ng} / \mathrm{mg}$ tissue. The line with squares is the actual data of $\alpha$-synuclein concentration; the straight line is the linear approximation of $\alpha$-synuclein concentration. 


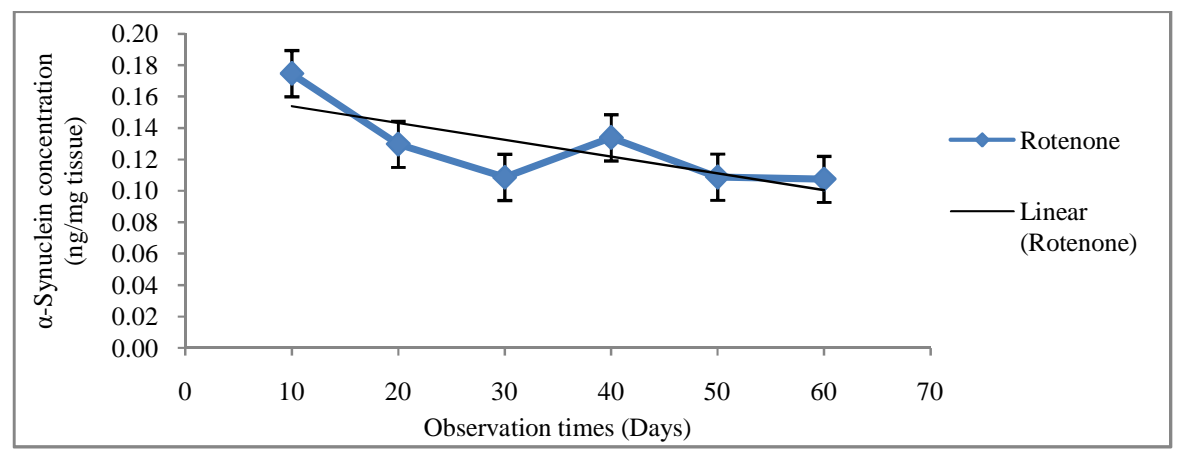

Figure 15 The $\alpha$-synuclein concentration of the rat's midbrain in the Rotenone Group tended to decrease, with the highest $\alpha$-synuclein concentration on day 10 $(0.17 \mathrm{ng} / \mathrm{mg}$ tissue $)$ and an average of $0.13 \pm 0.02 \mathrm{ng} / \mathrm{mg}$ tissue. The line with squares is the actual data of $\alpha$-synuclein concentration; the straight line is the linear approximation of $\alpha$-synuclein concentration.

The correlation between the oxidative stress index and the $\alpha$-synuclein concentration is shown in Table 1. In the Blank group, there was no correlation between oxidative stress and $\alpha$-synuclein concentration $(r=0.05, p=0.87)$. But in the Solvent-rotenone and the Rotenone groups, there are negative correlations ( $\mathrm{r}=-0.54, \mathrm{p}=0.07 ; \mathrm{r}=-0.6, \mathrm{p}=0.03$, respectively). This means that in the Rotenone group, the oxidative stress index was inversely proportional to the $\alpha$ synuclein concentration.

Table 1 Pearson Correlation between oxidative stress index and the $\alpha$ synuclein concentration in the midbrain of the rats treated with rotenone.

\begin{tabular}{cccc}
\hline \multirow{2}{*}{ Pearson Correlation $(\mathbf{r})$} & \multicolumn{3}{c}{ Oxidative Stress Index } \\
\cline { 2 - 4 } & Blank Group & $\begin{array}{c}\text { Solvent- } \\
\text { rotenone Group }\end{array}$ & $\begin{array}{c}\text { Rotenone } \\
\text { Group }\end{array}$ \\
\hline \multirow{2}{*}{$\boldsymbol{\alpha}$-synuclein } & $\begin{array}{c}\text { Solvent-rotenone } \\
\text { Group }\end{array}$ & $\begin{array}{c}0.055 \\
(\mathrm{p}=0.864)\end{array}$ & \\
& Rotenone Group & & \\
& & & \\
& & & -0.541 \\
\end{tabular}

\section{Discussion}

GSH is an endogenous antioxidant that is important for maintaining the redox balance in the cells [19]. Its importance is underlined by the fact that at the beginning, numerous diseases are an imbalance of the cellular redox system 
[20]. The mechanism controlling the oxidative stress depends on the action of the enzyme glutathione reductase that reduces two molecules of GSH to become one molecule of GSSG and, vice versa, reduces GSSG to maintain the redox balance in the cell. Thus, when GSSG is abundant in the cell, it becomes toxic. In dendritic cell cultures, an imbalance of the redox system activates p38 mitogen-activated protein kinases (MAPK) and leads to apoptosis [21]. In erythrocytes, an antioxidant decrease leads to an increase of GSSG and lipid peroxidation that is used as a biomarker of oxidative injury [22].

Under normal conditions, body weight tends to increase with age (Figure 1), similar to the GSH concentration (Figure 4), however, it is inversely proportional to the GSSG concentration (Figure 7). Meanwhile, in the rotenone treatment group, body weight was slightly down but tended to increase with age (Figure 3). Yet, the GSH concentration tended to decrease (Figure 6) inversely to the GSSG concentration (Figure 9). Based on these data, we believe that the rotenone caused oxidative stress in the midbrain of the rats. This is consistent with previous research [17, 23-26]. In this research, we found that the solvent used, i.e. sunflower seed oil, also had an effect on the oxidative stress in the midbrain of the rats (Figure 8). Although sunflower seed oil has a high nutritional value, it may interfere with fat metabolism.

Under normal physiological conditions, up to $1 \%$ of superoxide is formed by mitochondrial activity [11], but its endogenous antioxidants will immediately neutralize it. In other words, when the redox system is functional, the free radicals do not represent a major threat to the cells. In our study, the OSI for the Blank group was the highest of all groups. This indicates that the OSI is sensitive and rapidly changes, especially in mitochondria and cytosol [27], and therefore cannot be used to measure the oxidative stress condition in the neuron due to rotenone.

The $\alpha$-synuclein functions in the membrane of presynaptic neurons and the reason for its accumulation in cytosol still remain unclear. It is shown by our data that the $\alpha$-synuclein concentration has the same tendency in all groups, i.e. it is highest on day 10 and tends to decrease with age (Figure 13-15). An ELISA kit (MBS722815) was used to measure the $\alpha$-synuclein concentration for rat $\alpha$ synuclein, which is a 140 amino acid protein (Uniprot P37377); it is a soluble protein. Thus in our data, the $\alpha$-synuclein concentration measured is watersoluble protein. In the midbrain of Wistar rats, the water-solubility of the $\alpha$ synuclein tended to decrease with age, indicating that the solubility of the $\alpha$ synuclein was disturbed, and an aggregate protein may have been formed. Our goal for further research is to determine the conditions under which the $\alpha$ synuclein aggregates, forms fibrils, and forms cytoplasmic inclusion bodies, such as the Lewy bodies. 
Our research shows a negative correlation between the oxidative stress index and the $\alpha$-synuclein concentration in the midbrain of the Wistar rats treated with rotenone. This means that the oxidative stress index is inversely proportional to the $\alpha$-synuclein concentration. Thus, the increase of oxidative stress does not indicate an accumulation of $\alpha$-synuclein in the cells.

\section{Conclusion}

In our research, the midbrain of Wistar rats treated with rotenone was indicated under oxidative stress conditions. Water-soluble $\alpha$-synuclein protein tends to decrease with age; maybe after day 10, $\alpha$-synuclein protein-solubility begins to be disturbed. This indicates accumulation of $\alpha$-synuclein protein.

\section{References}

[1] Yang, J.O., Kim, W., Jeong, S., Oh, J., Jho, S., Bhak, J \& Kim, N., PD Base: A Database of Parkinson's Disease-Related Genes and Genetic Variation Using Substantia Nigra ESTs, Asia Pacific Bioinformatics Network (APBioNet) Eighth International Conference on Bioinformatics, BMC Genomics, pp. 1-7, 2009.

[2] Okubadejo, N.U., Ojo, O.O. \& Oshinaike, O.O., Clinical Profile of Parkinsonism and Parkinson's Disease in Lagos, Southwestern Nigeria, BMC Neurology, pp. 1-6, 2010.

[3] Bellinger, F.P., Bellinger, M.T., Seale, L.A., Takemoto, A.S., Arjun V. Raman, A.V., Miki, T, Amy B Manning-Boğ, A.B., Berry, M.J., White, L.R \& Ross, G.W., Glutathione Peroxidase 4 is Associated with Neuromelanin in Substantia Nigra and Dystrophic Axons in Putamen of Parkinson's Brain, Molecular Neurodegeneration, 6(8), pp. 1-10, 2011.

[4] Tapia-González, S., Giráldez-Pérez, R.M., Cuartero, M.I., Casarejos, M.J., Menal, M.A., Wang, X.F. \& Sánchez-Capelo, A., Dopamine and $\alpha$ Synuclein Dysfunction in Smad3 Null Mice, Molecular Neurodegeneration, 6(72), pp. 1-23, 2011.

[5] Bate, C., Gentleman, S. \&, Williams, A., $\alpha$-Synuclein Induced Synapse Damage is Enhanced by Amyloid-b1-42, Molecular Neurodegeneration, 5(55), pp. 1-9, 2010.

[6] Meng, F., Yao, D., Shi, Y., Kabakoff, J., Wu, W., Reicher, J., Ma, Y., Moosmann, B., Masliah, E., Lipton, S.A. \& Gu, Z., Oxidation of The Cysteine-Rich Regions of Parkin Perturbs Its E3 Ligase Activity and Contributes to Protein Aggregation, Molecular Neurodegeneration, 6(34), pp. 1-15, 2011.

[7] Lavedan, C., The Synuclein Family, Genome Research, pp. 1-11, 1998. 
[8] Maroteax, L., Campanelli, J.T. \& Scheller, R.H., Synuclein: A NeuronSpecific Protein Localized to the Nucleus and Presynaptic Nerve Terminal, The Journal of Neuroscience, 8(8), pp. 2804-2815, 1988.

[9] Cookson, M.R., $\alpha$-Synuclein and Neuronal Cell Death, Molecular Neurodegeneration, 4(9), pp. 1-14, 2009.

[10] Stefanis, L., $\alpha$-Synuclein in Parkinson's Disease, Cold Spring Harb Perspect Med, 2, pp. 1-24, 2011.

[11] Klein, J.A., Ackerman, S.L., Oxidative Stress, Cell Cycle, and Neurodegeneration, The Journal of Clinical Investigation, 111(6), pp. 785-793, 2003.

[12] Ischiropoulos, H. \& Beckman, J.S., Oxidative Stress and Nitration in Neurodegeneration: Cause, Effect, or Association?, The Journal of Clinical Investigation, 111, pp. 163-169, 2003.

[13] Muller, A.C., An Investigation into the Neuroprotective Properties of Acyclovir, Thesis Rhodes University, pp. 105-106, 2006.

[14] RAT Wistar and Sprague Dawley Strains, http://www.nlac.mahidol.ac.th/ nlacmuEN/p_animal_Rat.htm (8 November, 2012).

[15] Fang, Y.Z., Yang, S. \& Wu, G., Free Radicals, Antioxidants, and Nutrition, Nutrition, 18, pp. 872-879, 2002.

[16] Lauterburg, B.H., Smith, C.V., Hughes, H. \& Mitchell, J.R., Biliary Excretion of Glutathione and Glutathione Disulfide in the Rat Regulation and Response to Oxidative Stress, J. Clin. Invest, 73, pp. 124-133, 1984.

[17] Betarbet, R., Sherer, T.B., MacKenzie, G., Garcia-Osuna, M., Panov, A.V. \& Greenamyre, J.T., Chronic Systemic Pesticide Exposure Reproduces Features Parkinson's Disease, Nature Neuroscience, 3(12), pp. 1301-1306, 2000.

[18] Tsigelny, I.F., Crews, L., Desplats, P., Shaked, G.M., Sharikov, Y., Mizuno, H., Spencer B., Rochkenstein, E., Trejo, M., Platoshyn, O., Yuan, J.X.J. \& Masliah, E., Mechanisms of Hybrid Oligomer Formation in the Pathogenesis of combined Alzheimer's and Parkinson's Diseases, http://www.plosone.org/article/info/journal (18 October 2012).

[19] Ashtiani, H.R.A., Bkhshandi, A.K., Rahbar, M., Mirzaei, A., Malekpour, A. \& Rastegar, H., Glutathione, Cell Proliferation and Differentiation, African Journal of Biotechnology, 10(34), pp. 6348-6363, 2011.

[20] Castagne, V., Rougemont, M., Cuenod, M. \& Do, K.Q., Low Brain Glutathione and Ascorbic Acid Associated with Dopamine Uptake Inhibition During Rat's Development Induce Long-Term Cognitive Deficit: Relevance To Schizophrenia, Neurobiology of Disease, 15(1), pp. 93-105, 2004.

[21] Zeevalk, G.D., Manzino, L., Sonsalla, P.K. \& Bernard, L.P., Characterization of Intracellular Elevation of Glutathione (GSH) with Glutathione Monoethyl Ester and GSH in Brain and Neuronal Cultures: 
Relevance to Parkinson's Disease, Exp. Neurol., 203(2), pp. 512-520, 2007.

[22] Mizuashi, M., Ohtani, T., Nakagawa, S. \& Aiba, S., Redox Imbalance Induced by Contact Sensitizers Triggers the Maturation of Dendritic Cells, J. Invest. Dermatol, 124, pp. 579-586, 2005.

[23] Alam, M. \& Schmidt, W.J., Rotenone Destroys Dopaminergic Neurons and Induces Parkinsonian Symptoms in Rats, Behavioural Brain Research, 136, pp. 317-324, 2002.

[24] Panov, A., Dikalov, S., Shalbuyeva, N., Taylor G., Sherer, T. \& Greenamyre, J.T., Rotenone Model of Parkinson Disease, Multiple Brain Mitochondria Dysfunction after Short Termsystemic Rotenone Intoxication, Journal of Biochemistry, 280, pp. 4026-4035, 2005.

[25] Galvin, J.E., Interaction of Alpha-synuclein and Dopamine Metabolites in The Pathogenesis of Parkinson's Disease: a Case for the Selective Vulnerability of the Substantia Nigra, Acta Neuropathol., 112, pp. 115126, 2006.

[26] Swarnkara, S., Singha, S., Mathurb, R., Patrob, I.K. \& Natha, C., A Study to Correlate Rotenone Induced Biochemical Changes and Cerebral Damage in Brain Areas with Neuromuscular Coordination in Rats, Toxicology, 272, pp. 7-22, 2010.

[27] $\mathrm{Hu}$, J., Dong, L. \& Outten, C.E., The Redox Environment in the Mitochondrial Intermembrane Space is Maintained Separately from the Cytosol and Matrix, Journal of Biological Chemistry, 283(43), pp. 2912629134, 2008. 